\title{
Neurobehavioral Effects of Interferon- $\alpha$ in Patients with Hepatitis-C: Symptom Dimensions and Responsiveness to Paroxetine
}

\author{
Marcia D McNutt', Shuling Liu' ${ }^{2}$, Amita Manatunga ${ }^{2}$, Erica B Royster ${ }^{3}$, Charles L Raison ${ }^{4,5}$, \\ Bobbi J Woolwine ${ }^{4,5}$, Marina F Demetrashvili, ${ }^{4,5}$, Andrew H Miller ${ }^{4,5}$ and Dominique L Musselman*,6 \\ 'Department of Psychology, University of Miami, Miami, FL, USA; '2Department of Biostatistics, Rollins School of Public Health, Emory University, \\ Atlanta, GA, USA; ${ }^{3}$ H Lee Moffitt Cancer Center, Tampa, FL, USA; ${ }^{4}$ Department of Psychiatry and Behavioral Sciences, Emory University School of \\ Medicine, Atlanta, GA, USA; ${ }^{5}$ Winship Cancer Institute, Emory University, Atlanta, GA, USA; ${ }^{6}$ Department of Psychiatry and Behavioral Sciences, \\ University of Miami Leonard H Miller School of Medicine, Miami, FL, USA
}

In patients at high risk for recurrence of malignant melanoma, interferon- $\alpha$ (IFN- $\alpha$ ), a stimulator of innate immunity, appears to induce distinct neurobehavioral symptom dimensions: a mood and anxiety syndrome, and a neurovegetative syndrome, of which the former is responsive to prophylactic administration of paroxetine. We sought to determine whether symptom dimensions (and treatment responsiveness) arise in patients with hepatitis $C$ administered IFN- $\alpha$ and ribavirin. In a randomized, double-blind, 6-month study, 6I patients with hepatitis $C$ eligible for therapy with IFN- $\alpha$ and ribavirin received the antidepressant paroxetine $(n=28)$ or a placebo $(n=33)$. Study medication began 2 weeks before IFN- $\alpha$ /ribavirin therapy. Neuropsychiatric assessments included the 10-item Montgomery-Asberg Depression Rating Scale (MADRS). The items of the MADRS were grouped into depression, anxiety, cognitive dysfunction, and neurovegetative symptom dimensions, and analyzed using a mixed model. By 2 weeks of IFN- $\alpha /$ ribavirin therapy, all four dimensions increased, with the symptom dimensions of anxiety and cognitive dysfunction fluctuating and worsening, respectively, in both groups over time. The depression symptom dimension was significantly lower in the paroxetine treatment group $(p=0.04)$; severity of the neurovegetative symptom dimension was similar in both groups. Similar to patients with malignant melanoma receiving high-dose IFN- $\alpha$, the depression symptom dimension is more responsive to paroxetine treatment in individuals undergoing concomitant IFN- $\alpha$ /ribavirin therapy. However, the anxiety, cognitive dysfunction, and neurovegetative symptom dimensions appear less responsive to prophylactic paroxetine administration. Different neurobiologic pathways may contribute to the responsiveness of IFN- $\alpha$-induced symptom dimensions to antidepressant treatment, requiring relevant psychopharmacologic strategies.

Neuropsychopharmacology (2012) 37, |444-1454; doi:I0.1038/npp.20 I I.330; published online 22 February 2012

Keywords: hepatitis C; paroxetine; interferon- $\alpha$; ribavirin; depressive; neurovegetative

\section{INTRODUCTION}

The cytokine interferon- $\alpha$ (IFN- $\alpha$ ), a stimulator of innate immunity, has been used to treat a variety of malignant disorders and chronic viral infections, such as myelogenous leukemia, malignant melanoma, tuberculosis, and hepatitis C (Chang et al, 1997; Giosue et al, 2000; Manesis and Hadziyannis, 2001; Poynard et al, 1998; Talpaz et al, 1991;

*Correspondence: Dr DL Musselman, Department of Psychiatry and Behavioral Sciences, Mental Health Hospital Center, University of Miami Leonard H Miller School of Medicine, 1695 NW 9th Avenue, Rm 2506, Miami, FL 33|46, USA, Tel: + I 404723 836।, Fax: + I 305 355 9072, E-mail: dmusselman@med.miami.edu

Received 26 June 2011; revised I December 2011; accepted 6 December 2011
Wheatley et al, 2003). As one of the first FDA-approved treatments for chronic hepatitis C (Lindsay, 1997), a viral infection that affects approximately three to four million people in the United States of America (Centers for Disease Control and Prevention, 2011), IFN $-\alpha$ has been shown to induce neuropsychiatric symptoms, including depression and anhedonia (Yates and Gleason, 1998; Zdilar et al, 2000), as well as neurovegetative and somatic symptoms (eg, anorexia, fatigue, altered sleep) (Capuron et al, 2000; Kelley et al, 2003; Valentine et al, 1998). Approximately $10-45 \%$ of all patients receiving IFN- $\alpha$ therapy develop depressive symptoms during the course of their treatment depending on the dose (Zdilar et al, 2000). Moreover, residual psychiatric symptoms (depressed mood, anxiety, insomnia) may last for up to at least 6 months after cessation of IFN- $\alpha$ 
treatment (Hosoda et al, 2000). These IFN- $\alpha$-associated neurobehavioral symptoms diminish quality of life for patients, which may impact compliance with IFN- $\alpha$ treatment, thereby reducing its potential therapeutic benefit (DiMatteo et al, 2000; Ho et al, 2001; Kraus et al, 2001).

In recent years, the concept that symptoms cluster in groups has been examined in various disease populations (Dodd et al, 2001; Miaskowski et al, 2004; Walsh et al, 2000; Walsh and Rybicki, 2006). As demonstrated by hierarchical regression analyses, the relationships of symptoms within each cluster are stronger than those between clusters (Dodd et al, 2001; Kim et al, 2005), and appear stable over months of time (Kim et al, 2005; Kirkova and Walsh, 2007). For example, symptoms related to mood, cognitive impairment, and fatigue group together to form symptom clusters in women with breast cancer. All three of these symptom clusters have been shown to occur at three different phases of the disease (pre-adjuvant therapy, post-adjuvant therapy, and palliative care) (Bender et al, 2005). In another example, a symptom cluster consisting of fatigue, weakness, weight loss, appetite loss, nausea, vomiting, and altered taste, found in patients with lung cancer, was present at least 3-6 months after diagnosis (Gift et al, 2003). In that such clusters may reflect disease course, treatment adverse effects, or efficacy (Kim et al, 2005), the concept of symptom clusters has clinical utility in that targeting certain symptom clusters at specific time points of a disease and/or its treatment may reduce patient burden and improve quality of life (Bender et al, 2005; Chen and Tseng, 2006; Kirkova and Walsh, 2007; Wang et al, 2006). Interestingly, the notion of symptom clusters is not new. Clusters of somatic symptoms were described over 40 years ago in cross-sectional studies of patients with major mental disorders (Haward, 1979; Mahrer et al, 1966; Williams et al, 1976). More recently, symptom clusters of neuropsychiatric, gastrointestinal, and pain symptoms have been identified in untreated patients with chronic hepatitis C (Lang et al, 2006), and 'non-somatic' $v s$ neurovegetative depressive symptoms (ie, fatigue, loss of appetite, and sleep disturbance) of individuals with hepatitis C co-infected with HIV (Yoon et al, 2011). In the current study, we sought to determine the expression of neurobehavioral symptom clusters in patients with hepatitis $C$ receiving pegylated or non-pegylated IFN- $\alpha$ and ribavirin treatment therapy, and the responsiveness of such symptoms to paroxetine treatment.

\section{MATERIALS AND METHODS}

Eighty-two patients were screened between February 2000 and January 2005 at four academic medical centers (Atlanta, GA $(n=32)$, Philadelphia, PA $(n=9)$, New York, NY $(n=15)$, and Chicago, IL $(n=5))$ (Figure 1). Sixty-one patients (ages 18-65), who were serum positive for antihepatitis $\mathrm{C}$ virus antibodies or hepatitis $\mathrm{C}$ virus RNA by reverse transcription-PCR, were enrolled. This patient sample was identical to that reported by Raison et al (2007).

Exclusion criteria included the following: (1) diagnosis of major depression or substance abuse/dependence within 6 months of study entry; (2) history of schizophrenia or bipolar disorder (determined by Structured Clinical Interview for Diagnostic and Statistical Manual of Mental
Disorders - Fourth Edition (SCID-IV) (American Psychiatric Association, 1994)); (3) a score $<24$ on the Mini Mental State Exam (Folstein et al, 1975), indicating more than mild cognitive impairment; (4) individuals with decompensated liver disease; (5) liver disease of any cause other than hepatitis $C$ virus; and (6) unstable cardiovascular, endocrinologic, hematologic, renal, or neurologic disease. Patients were without psychotropic medications (except zolpidem for sleep) at least 2 weeks prior to baseline.

\section{Enrollment and Follow-up}

Patients completed a screening visit, and approximately 2 weeks later completed a baseline evaluation. At the end of this baseline evaluation (which occurred 2 weeks prior to IFN- $\alpha$ /ribivirin administration), the study subjects were randomly assigned in a double-blind manner to begin 26 weeks of either paroxetine (Paxil; GlaxoSmithKline, Philadelphia, PA, USA) or placebo. They commenced treatment with the study medication by ingesting one tablet of either paroxetine $(10 \mathrm{mg})$ or placebo once per day. After 3 days, the dose was raised to two tablets daily as tolerated. The study participants were then re-evaluated 2 weeks after the baseline evaluation and started on IFN- $\alpha /$ ribavirin therapy. At study week 4 (2 weeks after commencing IFN- $\alpha$ /ribavirin therapy), based on the depressive symptoms, study medication could be increased up to four tablets per day at the discretion of the study psychiatrists. The study participants were then re-evaluated every 4 weeks thereafter and received study medication for 26 weeks in duration unless they dropped out or were terminated. Concomitant psychotropic medications were not allowed during treatment, with the exception of zolpidem for insomnia.

Because this study occurred during transition to pegylated IFN- $\alpha, 22$ subjects received non-pegylated IFN- $\alpha-2 b$ (Intron A; Schering Plough, Kenilworth, NJ, USA), 20 received pegylated IFN- $\alpha-2 b$ (Pegintron; Schering Plough), and 10 received pegylated IFN- $\alpha$-2a (PEGASYS; Roche, Basel, Switzerland). The IFN- $\alpha$ /ribavirin dosage decisions were made by treating physicians and were not controlled by the study protocol.

\section{Assessments}

At each visit, trained clinicians administered the mood disorders module from the SCID-IV to determine whether patients fulfilled the criteria for major depressive disorder. Participants who fulfilled full criteria for depression continued their double-blind, placebo-controlled treatment. Depressive symptom severity was evaluated using the clinician-administered Montgomery-Asberg Depression Rating Scale (MADRS) (Montgomery and Asberg, 1979), a 10 -item scale sensitive to symptom change during antidepressant treatment. Scores for each item range from 0 to 6 (total possible score $=60$ ), with higher scores indicating greater symptom severity. As discussed previously (Raison et al, 2007), the MADRS has been frequently used to measure depressive symptoms during IFN- $\alpha$ therapy, and shows improved internal consistency in patients with comorbid medical conditions compared with other clinician-administered questionnaires (Bonaccorso et al, 2002; Capuron et al, 2000; Constant et al, 2005; Hammond, 1998; 


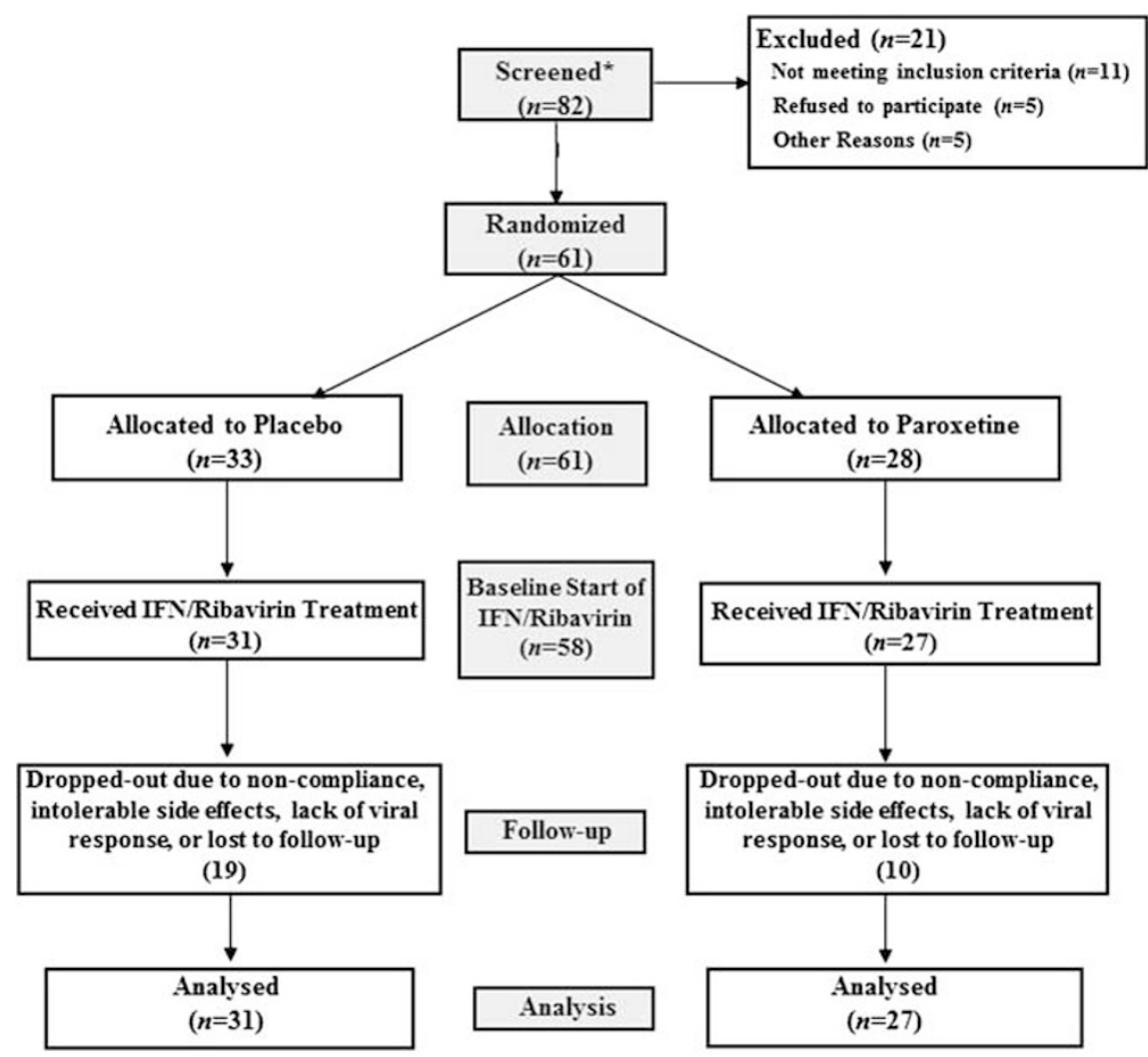

*The statistical analysis was performed based on the total number of non-missing cases.

Figure I Study flow diagram.

Khan et al, 2004; Wichers et al, 2005). In addition to providing a continuous score of depressive symptoms, the following scores for the MADRS have been correlated with global severity measures of depression and have been used as 'cut-off' scores for levels of severity of depressive symptoms: mild, 15; moderate, 25; and severe, 31 (Kearns et al, 1982; Yonkers and Samson, 2000). Training videotapes were used to enhance inter-rater reliability on the MADRS within and between study sites. The incidence of major depressive disorder in this patient sample has been reported elsewhere (Raison et al, 2007).

\section{Dimensional Analyses}

Four time points were chosen for the dimensional analyses in order to allow examination of the immediate $v s$ delayed neurobehavioral effects of IFN- $\alpha$ : (1) baseline (before initiating IFN- $\alpha /$ ribavirin therapy or study medication); (2) 2 weeks after initiation of IFN- $\alpha$ /ribavirin treatment (week 2 of therapy); (3) at the end of the third month of IFN- $\alpha$ /ribavirin treatment (week 12); and (4) at the end of the study (week 24).

To perform the dimensional analyses, neurobehavioral symptoms were grouped in four dimensions corresponding to depression, anxiety, cognitive dysfunction, and neurovegetative symptoms, respectively. The dimension of depression included the following MADRS items: apparent sadness, reported sadness, inability to feel, pessimistic thoughts, and suicidal thoughts. The dimension of anxiety was assessed by the single MADRS item of inner tension; the dimension of cognitive dysfunction was similarly assessed by a single MADRS item, observed symptoms of concentration difficulties. Neurovegetative symptoms were assessed by the following MADRS items: reduced sleep, reduced appetite, and lassitude. The mean score obtained by a patient in each dimension was calculated as the sum of the severity scores obtained by the patient in each of the symptoms in that dimension divided by the number of symptoms in that dimension. For example, the mean score obtained by a patient in the dimension of depression corresponded to the sum of the score on the five following items: apparent sadness, reported sadness, inability to feel, pessimistic thoughts, and suicidal thoughts, divided by five.

\section{Statistical Analyses}

After the screening visit (Figure 1) there were 33 patients randomized to placebo and 28 randomized to paroxetine. However, only 31 patients in the placebo-treated group and 27 participants in the paroxetine-treated group subsequently attended the baseline visit. Thus, the drop-out of study subjects resulted in $58 \%(19 / 33)$ and $36 \%(10 / 28)$ of the placebo-treated group and paroxetine-treated group, respectively, by the end of the study. The linear mixed model analysis used all observed data using the 'missing at random' assumption (Rubin, 1976). Imputation methods such as last observation carry forward were not used 
owing to their strong assumptions, and because it may not be reasonable to impute a large proportion of the data. Differences between placebo- and paroxetinetreated patients for categorical variables were assessed by $\chi^{2}$-test. Differences for continuous measurements were analyzed by independent-samples $t$-tests. Our data analysis is based on the models that adjusted for baseline (before administration of paroxetine or placebo study drug) symptom scores.

Mean scores of each symptom item in the MADRS questionnaire were also calculated. Based on the score of the items, prevalence of MADRS symptoms of at least moderate intensity ( 2 or greater on an MADRS item) was derived.

\section{RESULTS}

\section{Socio-demographic Characteristics of the Study Sample}

As detailed previously by Raison et al (2007), the sociodemographic characteristics of the study groups are depicted in Table 1. Patients assigned to paroxetine were slightly but significantly older $(51.1(\mathrm{SD}=6.5)$ vs $46.6(\mathrm{SD}=8.2)$ years; $p=0.02)$. There were no differences between groups regarding male:female ratio, race, education level, marital status, history of major depressive disorder or substance abuse, or screening MADRS score.

Table I Characteristics of Study Sample at Screening Visit

\begin{tabular}{|c|c|c|}
\hline Characteristic & $\begin{array}{l}\text { Placebo } \\
(n=33)\end{array}$ & $\begin{array}{l}\text { Paroxetine } \\
(n=28)\end{array}$ \\
\hline $\operatorname{Sex}(M / F)$ & $20 / 13$ & $15 / 13$ \\
\hline \multicolumn{3}{|l|}{ Age (years) } \\
\hline Mean (SD) & $46.6(8.2)$ & $51.1(6.5)$ \\
\hline Range & $28-65$ & $38-66$ \\
\hline \multicolumn{3}{|l|}{ Race, n (\%) } \\
\hline African American & $10(30.3)$ & $10(35.7)$ \\
\hline Caucasian & $17(51.5)$ & II (39.3) \\
\hline Hispanic & $5(15.2)$ & $7(25.0)$ \\
\hline Other & I (3.0) & $0(0.0)$ \\
\hline \multicolumn{3}{|l|}{ Education (\%) } \\
\hline Less than high school & $8(24.2)$ & $5(17.9)$ \\
\hline High school & $17(5 \mid .5)$ & $18(64.3)$ \\
\hline College, graduate school & $6(18.2)$ & $5(17.9)$ \\
\hline Unknown & $2(6.1)$ & $0(0.0)$ \\
\hline History of major depression, $n(\%)$ & $8(24 \%)$ & $7(25 \%)$ \\
\hline History of substance abuse, n (\%) & $21(64 \%)$ & $18(64 \%)$ \\
\hline \multicolumn{3}{|l|}{ Baseline MADRS (score) } \\
\hline Mean (SD) & $5.2(5.2)$ & $3.5(3.6)$ \\
\hline Median & 3.0 & 3.5 \\
\hline Range & $0-24$ & $0-15$ \\
\hline
\end{tabular}

\section{Drop-outs}

As reported previously, nine subjects exited the study after ingesting at least one dose of the study medication but prior to receiving IFN- $\alpha$ /ribavirin. Twenty subjects (or 38\%) dropped out of the study during IFN- $\alpha$ /ribavirin treatment but prior to study completion. Reasons for early discontinuation included intolerable side effects (placebo-treated patients $(n=15)$ vs paroxetine-treated patients $(n=5))$, protocol deviation, such as being lost to follow-up or noncompliance (placebo $(n=6) v s$ paroxetine $(n=4))$, and lack of viral response (placebo $(n=0)$ vs paroxetine $(n=1))$. Patients randomized to paroxetine had a significantly lower rate of study discontinuation after IFN- $\alpha$ / ribavirin therapy was initiated (paroxetine, $n=5 / 23(22 \%)$; placebo, $n=15 / 29$ (52\%); $p=0.03)$. No patients were removed from the study as a result of active substance abuse (Raison et al, 2007).

IFN- $\alpha$ /Ribavirin-Induced Neurotoxicity in Placebo- and Paroxetine-Treated Patients at Baseline and Over Time

Prior to randomization placebo or paroxetine, the mean baseline scores for the depression, cognitive dysfunction, anxiety, and neurovegetative symptom dimensions were similar in the two study groups (Table 2). By the second week of IFN- $\alpha /$ ribavirin therapy, all of the symptom dimensions had increased. However, over time, the depression symptom dimension score was significantly lower in the paroxetine treatment group than the placebo treatment group $(p=0.04)$. By contrast, for the anxiety and cognitive dysfunction symptom dimensions, time had significant effects; that is, anxiety and cognitive dysfunction symptoms fluctuated and worsened, respectively, over time (anxiety, $p=0.01$; cognitive dysfunction, $p<0.0001$ ). For the neurovegetative symptom dimension, neither treatment nor time had a significant influence on the change of scores. Lastly, no interaction between treatment and time was statistically significant for any of the four symptoms. The temporal evolution of the scores in each symptom dimension in placebo- $v s$ paroxetine-treated patients over the course of the study is depicted in Figure 2.

\section{Individual Symptom Items in Placebo- and Paroxetine-} Treated Patients

The mean scores of patients for each symptom item in MADRS during the study are demonstrated in Table 3. The mean scores in this table also indicate that the items in the neurovegetative symptom dimension (ie, reduced sleep, reduced appetite, and lassitude) are similar between the two groups at baseline. There is a difference between the groups at 24 weeks for the following two items: apparent sadness and inability to feel. Specifically, the mean scores for those items in the paroxetine group are less than those in placebo group, with less fluctuation in the paroxetine group for those items. However, in both treatment groups, with regard to 'inner tension', 'observed concentration difficulties', and 'lassitude', these symptoms worsened over time $(p<0.05)$.

The frequency and prevalence of symptoms of at least moderate intensity ( 2 or greater on an MADRS item) 
Table 2 Symptom Dimensions as assessed by the Montgomery-Asberg Depression Rating Scale at Baseline and Over Time in Patients with Hepatitis C Receiving IFN- $\alpha$ /Ribavirin and Undergoing Double-Blind, Placebo-Controlled Treatment with Paroxetine

\begin{tabular}{|c|c|c|c|c|c|c|c|c|c|}
\hline \multirow{4}{*}{$\begin{array}{l}\text { Symptom } \\
\text { dimensions }\end{array}$} & \multicolumn{8}{|c|}{ IFN- $\alpha$ treatment } & \multirow{4}{*}{$\begin{array}{l}\text { Comparison } \\
\text { at week } 24^{\text {b }}\end{array}$} \\
\hline & \multicolumn{4}{|c|}{ Placebo $^{a}(n=33)$} & \multicolumn{4}{|c|}{ Paroxetine $^{a}(n=28)$} & \\
\hline & Baseline & Week 2 & Week I2 & Week 24 & Baseline & Week 2 & Week I2 & Week 24 & \\
\hline & $(n=33)$ & $(n=29)$ & $(n=22)$ & $(n=14)$ & $(n=28)$ & $(n=22)$ & $(n=21)$ & $(n=18)$ & \\
\hline & $(0.09)$ & $(0.16)$ & $(0.15)$ & $(1.04)$ & $(0.05)$ & $(0.12)$ & $(0.09)$ & $(0.15)$ & \\
\hline \multirow[t]{2}{*}{ Anxious $^{d}$} & 0.91 & 1.21 & 0.82 & 1.29 & 0.68 & 0.82 & 0.71 & 1.39 & NS \\
\hline & $(0.19)$ & $(0.25)$ & $(0.26)$ & $(1.54)$ & $(0.22)$ & $(0.25)$ & $(0.24)$ & $(0.30)$ & \\
\hline \multirow[t]{2}{*}{ Neurovegetative } & 0.72 & 1.55 & 1.55 & 1.64 & 0.54 & 1.77 & 1.27 & 1.30 & NS \\
\hline & $(0.11)$ & $(0.20)$ & $(0.25)$ & $(1.41)$ & $(0.13)$ & $(0.29)$ & $(0.18)$ & $(0.23)$ & \\
\hline
\end{tabular}

Abbreviation: NS, non-significant.

All symptom dimensions were assessed by the Montgomery-Asberg Depression Rating Scale.

${ }^{a}$ Values are mean (SE) scores ranging from 0 to 5, with higher scores indicating more severe symptoms.

${ }^{b}$ For all outcomes, no interactions between treatment and time are found to be significant.

${ }^{c} P$-value corresponds to the null hypothesis that the mean scores for paroxetine-treated group are the same as the mean scores for placebo-treated group at 24 weeks.

dMean scores of anxious symptoms $(p=0.0 \mathrm{I})$ and cognitive symptoms $(p<0.000 \mathrm{I})$ change significantly over time for both groups.
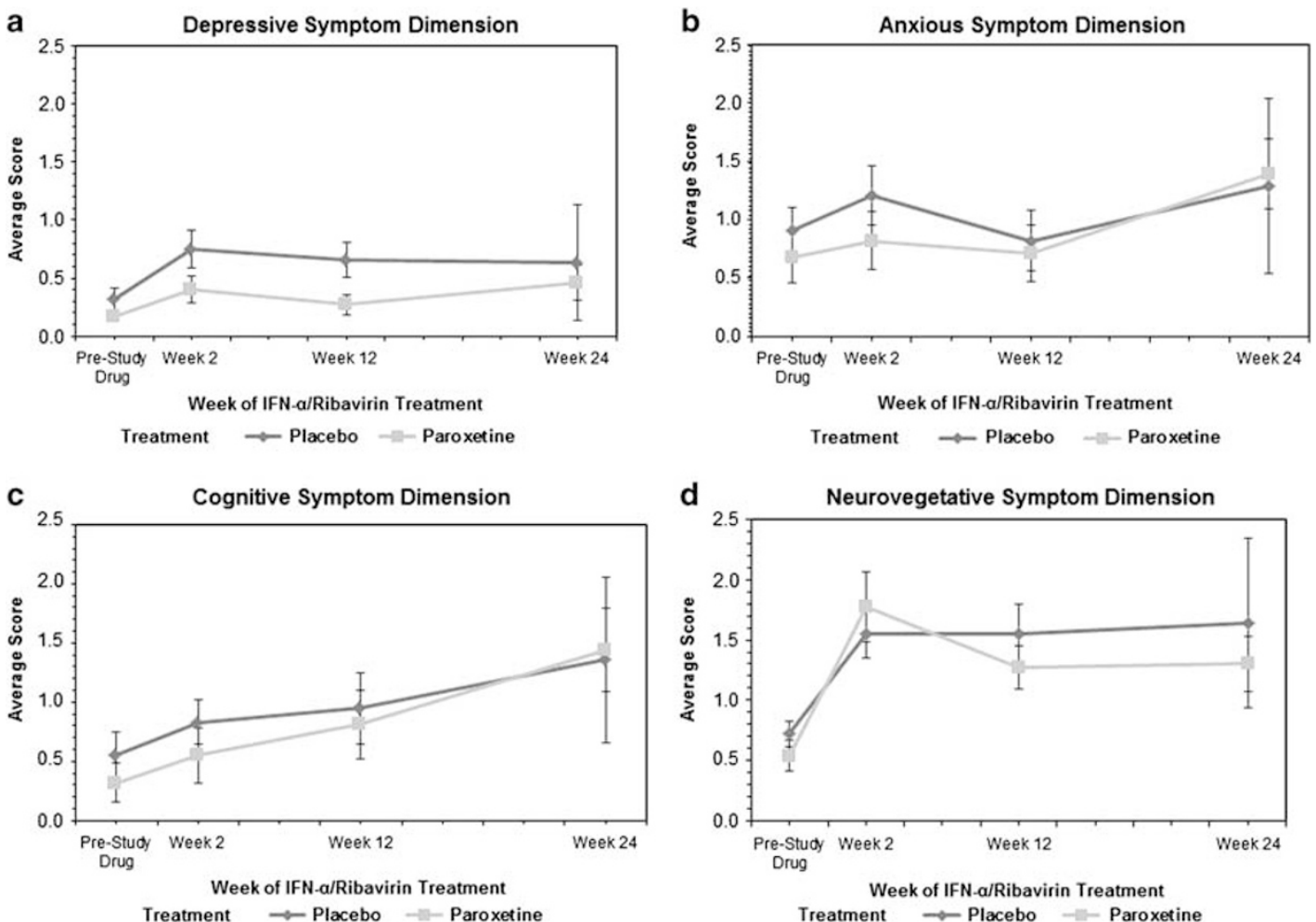

Figure 2 Symptom dimensions as assessed by the Montgomery-Asberg Depression Rating Scale in patients with hepatitis C receiving IFN- $\alpha$ /ribavirin therapy and undergoing double-blind, placebo-controlled treatment (mean with bars indicating standard error). (a) Depressive symptom dimension. (b) Anxious symptom dimension. (c) Cognitive symptom dimension. (d) Neurovegetative symptom dimension.

experienced by study participants during the course of IFN- $\alpha$ /ribavirin therapy are shown in Table 4 . Among all the symptoms listed, inner tension, reduced sleep, reduced appetite, and lassitude were symptoms experienced by at least $50 \%$ of patients receiving placebo or paroxetine while undergoing IFN- $\alpha /$ ribavirin therapy. 
Table 3 Mean of Specific Items of the Montgomery-Asberg Depression Anxiety Rating Scale at Baseline and Over Time in Patients with Hepatitis C Receiving IFN- $\alpha$ /Ribavirin and Undergoing Double-Blind, Placebo-Controlled Treatment with Paroxetine

Symptom items

IFN- $\alpha$ treatment

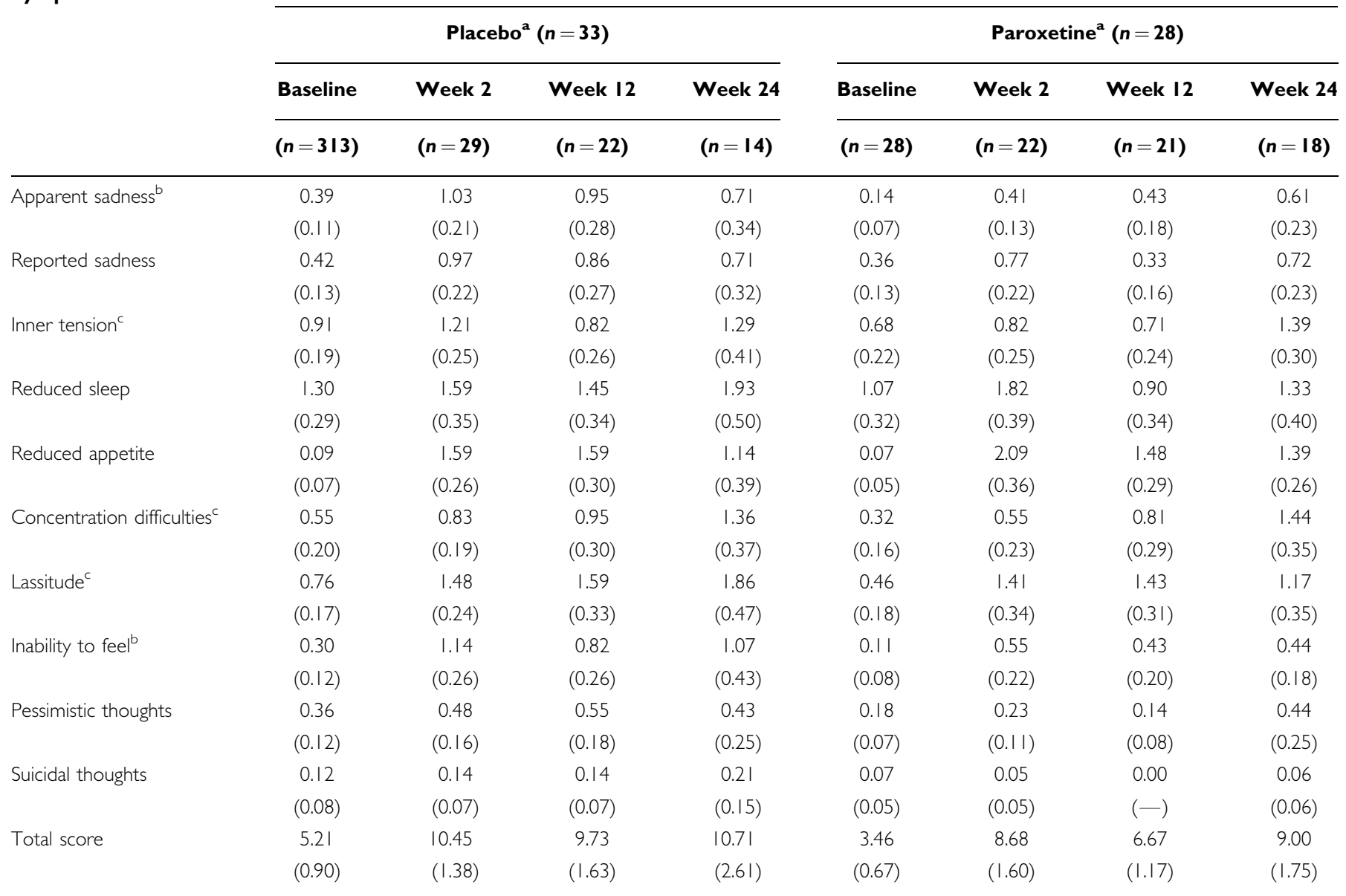

All symptom items were from the Montgomery-Asberg Depression Rating Scale.

${ }^{a} V a l u e s$ are mean (SE) scores ranging from 0 to 5, with higher scores indicating more severe symptoms.

${ }^{b}$ Mean scores of apparent sadness and inability to feel are significantly different between placebo- and paroxetine-treated groups at 24 weeks.

'There is a significant change of mean scores over time for lassitude, inner tension, and concentration difficulties in both groups.

Interactions between treatment and time are not significant for all variables.

\section{DISCUSSION}

There were four main findings of the present study. First, as ascertained using the MADRS, in this study population, all four symptom dimensions appeared by week 2 of IFN- $\alpha$ therapy, and continued in similar patterns between the two groups (with the exception of the neurovegetative symptoms by week 24). Such an 'early onset' of all four neurobehavioral symptom complexes in these patients, irrespective of their assignment to either placebo or paroxetine, might be related to a combination of virus and 'host' response. Relevant in this regard are prior studies documenting that most IFN- $\alpha$-induced depressive symptoms arise within 8 weeks (Wichers et al, 2005), and others demonstrating presence of hepatitis $\mathrm{C}$ within not only the cerebrospinal fluid (Bagaglio et al, 2005; Laskus et al, 2002; Maggi et al, 1999; Morsica et al, 1997) but the brain as well (Murray et al, 2008). Furthermore, not only do depressive symptoms in patients with chronic hepatitis C correlate with elevated peripheral plasma concentrations of interleukin-1 $\beta$ (IL-1 $\beta$ ) and tumor necrosis factor- $\alpha$ (Loftis et al, 2008), but exposure to hepatitis $C$ core protein induces microglial expression of pro-inflammatory cytokines such as IL- $1 \beta$, IL- 6 , and tumor necrosis factor- $\alpha$. With administration of IFN- $\alpha$, the enzyme indoleamine-2,3-dioxygenase (IDO) is activated within microglia and other cells, resulting in catabolism of tryptophan to L-kynurenine (KYN) and its neuroactive metabolites, including quinolinic acid (QUIN) and kynurenic acid (Raison et al, 2010; Vargas et al, 2002; Weissenborn et al, 2006). Indeed, in patients with hepatitis $\mathrm{C}$ receiving IFN- $\alpha /$ ribavirin, the CSF concentrations of KYN and QUIN correlate significantly with MADRS scores (Raison et al, 2010), and preclinical studies demonstrate that peripheral injection of KYN alone can induce depressive symptoms in rodents (O'Connor et al, 2009; Vecsei and Beal, 1990). Moreover, QUIN, produced in the CNS by microglia or infiltrating monocytes/macrophages (in amounts 20 -fold greater than microglia) (Pemberton 
Table 4 Percentage of Patients with Hepatitis C Experiencing Moderate-to-Severe Intensity (Endorsement of '2' or Greater per Item of the Montgomery-Asberg Depression Rating Scale) During IFN- $\alpha /$ Ribavirin Therapy

Symptom items

IFN $-\alpha$ treatment

\begin{tabular}{|c|c|c|c|c|c|c|c|}
\hline \multicolumn{4}{|c|}{ Placebo $^{a}(n=3 I)$} & \multicolumn{4}{|c|}{ Paroxetine $^{a}(n=28)$} \\
\hline Baseline & Week 2 & Week 12 & Week 24 & Baseline & Week 2 & Week 12 & Week 24 \\
\hline 9 & 31 & 27 & 29 & 0 & 5 & 10 & 22 \\
\hline 9 & 28 & 27 & 21 & 11 & 23 & 5 & 22 \\
\hline 24 & 34 & 27 & 43 & 21 & 27 & 24 & 56 \\
\hline 33 & 41 & 50 & 57 & 32 & 50 & 29 & 33 \\
\hline 3 & 55 & 59 & 43 & 0 & 68 & 57 & 61 \\
\hline 18 & 24 & 32 & 50 & 7 & 23 & 29 & 50 \\
\hline 15 & 41 & 50 & 57 & 14 & 41 & 52 & 28 \\
\hline 12 & 34 & 23 & 36 & 4 & 14 & 10 & 17 \\
\hline 6 & 17 & 14 & 14 & 0 & 5 & 0 & 11 \\
\hline 6 & 0 & 0 & 7 & 0 & 0 & 0 & 0 \\
\hline
\end{tabular}

et al, 1997), exerts a potent neurotoxic effect and is involved in neurodegenerative brain disorders, including AIDS dementia complex, Alzheimer's disease, amyotropic lateral sclerosis, Huntington's disease, multiple sclerosis, and Parkinson's disease (Guillemin et al, 2005).

Second, the depression symptom dimension score was significantly lower in the paroxetine treatment group than the placebo treatment group. Recent studies by Morasco et al (2007) (2010), which did not use symptom clusters to assess SSRI efficacy, are relevant in this regard. In Morasco's 2007 study (Morasco et al, 2007), although prophylactic use of paroxetine did not decrease the likelihood of IFN- $\alpha$-induced depression $(35.7 \%$ in the paroxetine group $v s 31.6 \%$ in the placebo group), in 10 of 11 patients who developed IFN- $\alpha$-induced depression and entered the rescue arm of the study, open-label treatment with paroxetine reduced depression symptoms, consistent with a previous open-label study using SSRIs for treatment of IFN-induced depression (Hauser et al, 2002). In their second trial, Morasco et al (2010) examined the impact of baseline depression severity scores on response to prophylactic treatment using citalopram $v s$ placebo in preventing IFN- $\alpha$-induced depression in hepatitis $C$ patients. Only 1 of 23 participants with an MADRS score below the median $(<3)$ developed IFN- $\alpha$-induced depression. In participants with baseline scores above the median on the MADRS (4), randomization to citalopram treatment provided preliminary support for preventing IFN- $\alpha$-induced depression; only 1 of 7 patients randomly assigned to citalopram (14\%) developed IFN- $\alpha$-induced depression, compared with 4 of 9 assigned to placebo (44\%). However, the differences between groups did not achieve statistical significance $\left(\chi^{2}=1.7 ; p=0.31\right)$. Collectively, these findings are generally consistent with this study's 'parent' 2007 investigation by Raison et al, who demonstrated that prophylactic, randomized treatment with paroxetine significantly reduced depressive symptom severity in comparison with placebo. This effect was largely accounted for by participants with hepatitis $C$ with MADRS depression scores above the median (MADRS $>3$ ) at baseline in whom paroxetine was associated with a maximal reduction in MADRS scores of 10.3 (95\% CI: $2.1-18.5$ ) compared with placebo at 20 weeks $(p<0.01)$. The differences in findings between the Raison et al (2007) and Morasco et al (2007) studies may be due at least in part to differences in patient populations (ie, those who clear hepatitis $\mathrm{C}$ virus are less likely to show depressive symptoms (Raison et al, 2005b)); polymorphisms in serotonin receptor genes (HTR1B, HTR2A, HTR5A, and HTR6), the serotonin transporter gene (SLC6A4) (Wilkie et al, 2009), the promoter region of the IFN- $\alpha / \beta$ receptor-1 (Yoshida et al, 2005), the IL-6 gene (Bull et al, 2009), or an IFN- $\gamma$ genotype (Oxenkrug et al, 2011); or higher dosages of concomitant ribavirin (Raison et al, 2005a).

Third, the anxiety and cognitive dysfunction symptom dimensions fluctuated and worsened, respectively, over 24 weeks. Of note is that the magnitude of these two symptom dimensions were not significantly different in subjects receiving paroxetine, despite the potential of this SSRI antidepressant to induce akathisia and anticholinergicassociated impairment of cognitive performance (Teva Pharmaceuticals USA, 2011). Our estimation of the anxiety and cognitive dysfunction dimensions, however, may be erroneous in that a single MADRS item of 'inner tension' and another, 'observed symptoms of concentration difficulties,' were used to index these two symptom dimensions. Another weakness of the study, which may have affected measurement of this symptom dimension, was that no inter-rater reliability for the MADRS was calculated among the sites, although all sites were required to review the same series of taped interviews and match their ratings to a standard metric. The likelihood that ribavirin was a contributing factor to the increasing magnitude of the anxiety and cognitive dysfunction symptom complexes in this study appeared small, given another large study, which showed, when compared with IFN- $\alpha$ therapy alone, that addition of ribavirin to IFN- $\alpha$ therapy for treatment of 
hepatitis C did not elevate the incidence of anxiety or impaired concentration (McHutchison et al, 1998). Given recent discoveries of hepatitis $\mathrm{C}$ virus within the brain, poor concentration may represent a neurocognitive 'biomarker' of central innate immune activation, given that significant differences have been documented in measures of concentration and information processing speed between patients with chronic hepatitis C infection, in comparison with patients who clear the virus and healthy volunteers (Forton et al, 2002).

Fourth, the neurovegetative symptom complex (ie, 'reduced sleep', 'reduced appetite', and 'lassitude') also was not responsive to paroxetine treatment. Over half of our study participants reported reduced sleep, decreased appetite, and lassitude. The incidence of reduced appetite in the paroxetine-treated patients with hepatitis $C$ is in contrast to studies documenting paroxetine-associated weight gain (Serretti and Mandelli, 2010), and may reflect symptoms of hepatitis $C$ viral infection and/or the anorexia, nausea, and diarrhea associated with IFN- $\alpha$ /ribavirin therapy (Seyam et al, 2005). Interestingly, a polymorphism of phospholipase A2 (PLA2), a key enzyme in the inflammatory response, has been studied by Pariante and co-workers in Han Chinese individuals with hepatitis C. Not only was the PLA2 Banl GG polymorphism associated with a higher-risk of IFN- $\alpha$-induced depression, but also with a 'somatic symptom cluster' as indexed by three items of the Hamilton Depression Rating Scale, 'GI and autonomic symptoms', 'reduced appetite', and 'loss of energy' (Su et al, 2010). Furthermore, another polymorphism, the ' $C$ ' allele of the IL-28B gene, has been associated with both sustained viral response to IFN therapy and IFN-induced neurovegetative symptoms (ie, decreased subjective appetite, reduced energy, and sleep complaints) indexed by the Beck Depression Rating Scale (Ge et al, 2009; Lotrich et al, 2011).

\section{CONCLUSION}

As discussed by Kirkova et al (2010), symptom clusters appear to vary with the assessment tool, disease stage, cluster methodology, and number of symptoms assessed; certainly validity and reliability of symptom clusters need universally accepted statistical methods, assessment tools, and symptom domains. Nevertheless, future neuropsychiatric studies of patients with hepatitis C receiving IFN- $\alpha$ and ribavirin may confirm this study's findings that depressive, anxiety, cognitive dysfunction, and neurovegetative symptom dimensions arise quickly, and persist, with only the IFN- $\alpha$-induced depression symptom dimension responding to prophylactic SSRI antidepressant treatment. Indeed, the limited effects of SSRI treatment upon IFN- $\alpha$-induced fatigue and other neurovegetative symptoms support the notion that IFN $-\alpha$ alters the pathways of monoamines other than serotonin (Miller, 2009). Relevant in this regard is that IFN- $\alpha$ activates IDO and mitogen-activated protein kinase pathways, which influence the synthesis, release, and reuptake of serotonin and dopamine (DA). Indeed, data from our laboratory and others support the concept that IFN- $\alpha$, as well as other innate immune cytokines, may profoundly alter DA metabolism and the function of basal ganglia circuits, thereby contributing to cytokine-induced neurovegetative symptoms, including fatigue, psychomotor slowing, and sleep disturbances (Capuron and Miller, 2004; Horikawa et al, 1999; Kamata et al, 2000; Kumai et al, 2000; Schaefer et al, 2003; Shuto et al, 1997; Sunami et al, 2000). State-of-the-art clinical trials using dopaminergic agonists in patients suffering IFN- $\alpha$-induced CNS dysfunction are desperately needed to assess their response to such comparative and adaptive pharmacologic treatment, and concomitantly improve the understanding of the mechanistic pathways involved. Given the high rates of substance use disorders in this patient population, however, and the possibility that DA agonists may contribute to impulse dyscontrol, such trials must closely monitor whether dopaminergic agonists complicate the clinical management of patients with hepatitis C (Ambermoon et al, 2011).

The resulting information may then ultimately improve the treatment of IFN- $\alpha$-treated patients, and other medically ill persons with prolonged neurovegetative symptoms induced by innate immune system activation (Auyeung et al, 2009).

\section{ACKNOWLEDGEMENTS}

We thank the many patients who gave their time and effort to help complete this study. The trial is registered with ClinicalTrials.gov under identifier NCT00352885. This work was supported by Schering-Plough and GlaxoSmithKline, and by grants from the National Institute of Mental Health (MH060723, MH64619, MH00680, MH071580, and MH60723) and an NIH/NCRR General Clinical Research Center grant (M01 RR00039).

\section{DISCLOSURE}

Charles L Raison serves as a consultant for Biolex Therapeutics and Pamlab. Andrew H Miller has served as consultant for Abbott Laboratories, AstraZeneca, GlaxoSmithKline, Lundbeck Research USA, F Hoffmann-La Roche, Schering-Plough Research Institute, and Wyeth/Pfizer, and has received research support from Centocor, GlaxoSmithKline, and Schering-Plough Research Institute. The remaining authors declare no conflict of interest.

\section{REFERENCES}

Ambermoon P, Carter A, Hall WD, Dissanayaka NN, O'Sullivan JD (2011). Impulse control disorders in patients with Parkinson's disease receiving dopamine replacement therapy: evidence and implications for the addictions field. Addiction 106: 283-293.

American Psychiatric Association (1994). Diagnostic and Statistical Manual of Mental Disorders: DSM-IV 4th edn American Psychiatric Association: Washington, DC.

Auyeung SF, Long Q, Royster EB, Murthy S, McNutt MD, Lawson $\mathrm{DH}$ et al (2009). Sequential multiple-assignment randomized trial design of neurobehavioral treatment for patients with metastatic malignant melanoma undergoing high-dose interferon-alpha therapy. Clin Trials 6: 480-490.

Bagaglio S, Cinque P, Racca S, Pedale R, Grasso MA, Lazzarin A et al (2005). Hepatitis C virus populations in the plasma, peripheral blood mononuclear cells and cerebrospinal fluid of HIV/hepatitis C virus-co-infected patients. AIDS 19(Suppl 3): S151-S165. 
Bender CM, Ergyn FS, Rosenzweig MQ, Cohen SM, Sereika SM (2005). Symptom clusters in breast cancer across 3 phases of the disease. Cancer Nurs 28: 219-225.

Bonaccorso S, Marino V, Puzella A, Pasquini M, Biondi M, Artini $M$ et al (2002). Increased depressive ratings in patients with hepatitis $\mathrm{C}$ receiving interferon-alpha-based immunotherapy are related to interferon-alpha-induced changes in the serotonergic system. J Clin Psychopharmacol 22: 86-90.

Bull SJ, Huezo-Diaz P, Binder EB, Cubells JF, Ranjith G, Maddock $C$ et al (2009). Functional polymorphisms in the interleukin-6 and serotonin transporter genes, and depression and fatigue induced by interferon-alpha and ribavirin treatment. Mol Psychiatry 14: 1095-1104.

Capuron L, Miller AH (2004). Cytokines and psychopathology: lessons from interferon-alpha. Biol Psychiatry 56: 819-824.

Capuron L, Ravaud A, Dantzer R (2000). Early depressive symptoms in cancer patients receiving interleukin 2 and/or interferon alfa-2b therapy. J Clin Oncol 18: 2143-2151.

Centers for Disease Control and Prevention (2011). Hepatitis C information for health professionals. http://www.cdc.gov/ hepatitis/HCV/index.htm.

Chang E, Boyd A, Nelson CC, Crowley D, Law T, Keough KM et al (1997). Successful treatment of infantile hemangiomas with interferon-alpha-2b. J Pediatr Hematol Oncol 19: 237-244.

Chen ML, Tseng HC (2006). Symptom clusters in cancer patients. Support Care Cancer 14: 825-830.

Constant A, Castera L, Dantzer R, Couzigou P, de Ledinghen V, Demotes-Mainard J et al (2005). Mood alterations during interferon-alfa therapy in patients with chronic hepatitis C: evidence for an overlap between manic/hypomanic and depressive symptoms. J Clin Psychiatry 66: 1050-1057.

DiMatteo MR, Lepper HS, Croghan TW (2000). Depression is a risk factor for noncompliance with medical treatment: meta-analysis of the effects of anxiety and depression on patient adherence. Arch Intern Med 160: 2101-2107.

Dodd MJ, Miaskowski C, Paul SM (2001). Symptom clusters and their effect on the functional status of patients with cancer. Oncol Nurs Forum 28: 465-470.

Folstein MF, Folstein SE, McHugh A (1975). 'Mini-Mental State': a practical method for grading the cognitive state of patients for the clinician. J Psychiatr Res 12: 189-198.

Forton DM, Thomas HC, Murphy CA, Allsop JM, Foster GR, Main J et al (2002). Hepatitis $C$ and cognitive impairment in a cohort of patients with mild liver disease. Hepatology 35: 433-439.

Ge D, Fellay J, Thompson AJ, Simon JS, Shianna KV, Urban TJ et al (2009). Genetic variation in IL28B predicts hepatitis C treatmentinduced viral clearance. Nature 461: 399-401.

Gift AG, Stommel M, Jablonski A, Given W (2003). A cluster of symptoms over time in patients with lung cancer. Nurs Res 52: 393-400.

Giosue S, Casarini M, Ameglio F, Zangrilli P, Palla M, Altieri AM et al (2000). Aerosolized interferon-alpha treatment in patients with multi-drug-resistant pulmonary tuberculosis. Eur Cytokine Netw 11: 99-104.

Guillemin GJ, Wang L, Brew BJ (2005). Quinolinic acid selectively induces apoptosis of human astrocytes: potential role in AIDS dementia complex. J Neuroinflammation 2: 16.

Hammond MF (1998). Rating depression severity in the elderly physically ill patient: reliability and factor structure of the Hamilton and the Montgomery-Asberg depression rating scales. Int J Geriatr Psychiatry 13: 257-261.

Hauser P, Khosla J, Aurora H, Laurin J, Kling MA, Hill J et al (2002). A prospective study of the incidence and open-label treatment of interferon-induced major depressive disorder in patients with hepatitis C. Mol Psychiatry 7: 942-947.

Haward LR (1979). Multivariate symptom analysis related to response to lorazepam treatment. Curr Med Res Opin 6: 20-23.
Ho SB, Nguyen H, Tetrick LL, Opitz GA, Basara ML, Dieperink E (2001). Influence of psychiatric diagnoses on interferon-alpha treatment for chronic hepatitis $\mathrm{C}$ in a veteran population. $\mathrm{Am} \mathrm{J}$ Gastroenterol 96: 157-164.

Horikawa N, Yamazaki T, Sagawa M, Nagata T (1999). A case of akathisia during interferon-alpha therapy for chronic hepatitis type C. Gen Hosp Psychiatry 21: 134-135.

Hosoda S, Takimura H, Shibayama M, Kanamura H, Ikeda K, Kumada H (2000). Psychiatric symptoms related to interferon therapy for chronic hepatitis C: clinical features and prognosis. Psychiatry Clin Neurosci 54: 565-572.

Kamata M, Higuchi H, Yoshimoto M, Yoshida K, Shimizu T (2000). Effect of single intracerebroventricular injection of alpha-interferon on monoamine concentrations in the rat brain. Eur Neuropsychopharmacol 10: 129-132.

Kearns NP, Cruickshank CA, McGuigan KJ, Riley SA, Shaw SP, Snaith RP (1982). A comparison of depression rating scales. $\mathrm{Br} \mathrm{J}$ Psychiatry 141: 45-49.

Kelley KW, Bluthe RM, Dantzer R, Zhou JH, Shen WH, Johnson RW et al (2003). Cytokine-induced sickness behavior. Brain Behav Immun 17(Suppl 1): S112-S118.

Khan A, Brodhead AE, Kolts RL (2004). Relative sensitivity of the Montgomery-Asberg depression rating scale, the Hamilton depression rating scale and the clinical global impressions rating scale in antidepressant clinical trials: a replication analysis. Int Clin Psychopharmacol 19: 157-160.

Kim HJ, McGuire DB, Tulman L, Barsevick AM (2005). Symptom clusters: concept analysis and clinical implications for cancer nursing. Cancer Nurs 28: 270-282.

Kirkova J, Walsh D (2007). Cancer symptom clusters - a dynamic construct. Support Care Cancer 15: 1011-1013.

Kirkova J, Walsh D, Aktas A, Davis MP (2010). Cancer symptom clusters: old concept but new data. Am J Hosp Palliat Care 27: 282-288.

Kraus MR, Schafer A, Csef H, Faller H, Mork H, Scheurlen M (2001). Compliance with therapy in patients with chronic hepatitis C: associations with psychiatric symptoms, interpersonal problems, and mode of acquisition. Dig Dis Sci 46: 2060-2065.

Kumai T, Tateishi T, Tanaka M, Watanabe M, Shimizu H, Kobayashi S (2000). Effect of interferon-alpha on tyrosine hydroxylase and catecholamine levels in the brain of rats. Life Sci 67: 663-669.

Lang CA, Conrad S, Garrett L, Battistutta D, Cooksley WG, Dunne MP et al (2006). Symptom prevalence and clustering of symptoms in people living with chronic hepatitis $\mathrm{C}$ infection. J Pain Symptom Manage 31: 335-344.

Laskus T, Radkowski M, Bednarska A, Wilkinson J, Adair D, Nowicki $M$ et al (2002). Detection and analysis of hepatitis C virus sequences in cerebrospinal fluid. J Virol 76: 10064-10068.

Lindsay KL (1997). Therapy of hepatitis C: overview. Hepatology 26(3 Suppl 1): 71S-77S.

Loftis JM, Huckans M, Ruimy S, Hinrichs DJ, Hauser P (2008). Depressive symptoms in patients with chronic hepatitis $\mathrm{C}$ are correlated with elevated plasma levels of interleukin1beta and tumor necrosis factor-alpha. Neurosci Lett 430: 264-268.

Lotrich FE, Loftis JM, Ferrell RE, Rabinovitz M, Hauser P (2011). IL28B polymorphism is associated with both side effects and clearance of hepatitis $\mathrm{C}$ during interferon-alpha therapy. J Interferon Cytokine Res 31: 331-336.

Maggi F, Giorgi M, Fornai C, Morrica A, Vatteroni ML, Pistello M et al (1999). Detection and quasispecies analysis of hepatitis C virus in the cerebrospinal fluid of infected patients. J Neurovirol 5: 319-323.

Mahrer AR, Mason DJ, Rosenshine M (1966). A headache syndrome in psychiatric patients: symptom clusters accompanying headaches. J Clin Psychol 22: 411-414. 
Manesis EK, Hadziyannis SJ (2001). Interferon alpha treatment and retreatment of hepatitis $B$ e antigen-negative chronic hepatitis B. Gastroenterology 121: 101-109.

McHutchison JG, Gordon SC, Schiff ER, Shiffman ML, Lee WM, Rustgi VK et al (1998). Interferon alfa-2b alone or in combination with ribavirin as initial treatment for chronic hepatitis C. Hepatitis Interventional Therapy Group. $N$ Engl J Med 339: 1485-1492.

Miaskowski C, Dodd M, Lee K (2004). Symptom clusters: the new frontier in symptom management research. J Natl Cancer Inst Monogr 32: 17-21.

Miller AH (2009). Norman cousins lecture. Mechanisms of cytokine-induced behavioral changes: psychoneuroimmunology at the translational interface. Brain Behav Immun 23: 149-158.

Montgomery SA, Asberg M (1979). A new depression scale designed to be sensitive to change. $\mathrm{Br} J$ Psychiatry 134: 382-389.

Morasco BJ, Loftis JM, Indest DW, Ruimy S, Davison JW, Felker B et al (2010). Prophylactic antidepressant treatment in patients with hepatitis $\mathrm{C}$ on antiviral therapy: a double-blind, placebocontrolled trial. Psychosomatics 51: 401-408.

Morasco BJ, Rifai MA, Loftis JM, Indest DW, Moles JK, Hauser P (2007). A randomized trial of paroxetine to prevent interferonalpha-induced depression in patients with hepatitis C. J Affect Disord 103: 83-90.

Morsica G, Bernardi MT, Novati R, Uberti Foppa C, Castagna A, Lazzarin A (1997). Detection of hepatitis C virus genomic sequences in the cerebrospinal fluid of HIV-infected patients. $J$ Med Virol 53: 252-254.

Murray J, Fishman SL, Ryan E, Eng FJ, Walewski JL, Branch AD et al (2008). Clinicopathologic correlates of hepatitis $C$ virus in brain: a pilot study. J Neurovirol 14: 17-27.

O'Connor JC, Lawson MA, Andre C, Moreau M, Lestage J, Castanon N et al (2009). Lipopolysaccharide-induced depressive-like behavior is mediated by indoleamine 2,3-dioxygenase activation in mice. Mol Psychiatry 14: 511-522.

Oxenkrug G, Perianayagam M, Mikolich D, Requintina P, Shick L, Ruthazer $\mathrm{R}$ et al (2011). Interferon-gamma (+874) T/A genotypes and risk of IFN-alpha-induced depression. J Neural Transm 118: 271-274.

Pemberton LA, Kerr SJ, Smythe G, Brew BJ (1997). Quinolinic acid production by macrophages stimulated with IFN-gamma, TNFalpha, and IFN-alpha. J Interferon Cytokine Res 17: 589-595.

Poynard T, Marcellin P, Lee SS, Niederau C, Minuk GS, Ideo G et al (1998). Randomised trial of interferon alpha2b plus ribavirin for 48 weeks or for 24 weeks $v s$ interferon alpha2b plus placebo for 48 weeks for treatment of chronic infection with hepatitis $\mathrm{C}$ virus. International Hepatitis Interventional Therapy Group (IHIT). Lancet 352: 1426-1432.

Raison CL, Borisov AS, Broadwell SD, Capuron L, Woolwine BJ, Jacobson IM et al (2005a). Depression during pegylated interferon-alpha plus ribavirin therapy: prevalence and prediction. J Clin Psychiatry 66: 41-48.

Raison CL, Broadwell SD, Borisov AS, Manatunga AK, Capuron L, Woolwine BJ et al (2005b). Depressive symptoms and viral clearance in patients receiving interferon-alpha and ribavirin for hepatitis C. Brain Behav Immun 19: 23-27.

Raison CL, Dantzer R, Kelley KW, Lawson MA, Woolwine BJ, Vogt $\mathrm{G}$ et al (2010). CSF concentrations of brain tryptophan and kynurenines during immune stimulation with IFN-alpha: relationship to CNS immune responses and depression. Mol Psychiatry 15: 393-403.

Raison CL, Woolwine BJ, Demetrashvili MF, Borisov AS, Weinreib $\mathrm{R}$, Staab JP et al (2007). Paroxetine for prevention of depressive symptoms induced by interferon-alpha and ribavirin for hepatitis C. Alimentary Pharm Therapeutics 25: 1163-1174.

Rubin DB (1976). Inference and missing data. Biometrika 63: 581-592.
Schaefer M, Schwaiger M, Pich M, Lieb K, Heinz A (2003). Neurotransmitter changes by interferon-alpha and therapeutic implications. Pharmacopsychiatry 36(Suppl 3): S203-S206.

Serretti A, Mandelli L (2010). Antidepressants and body weight: a comprehensive review and meta-analysis. J Clin Psychiatry 71: 1259-1272.

Seyam MS, Freshwater DA, O'Donnell K, Mutimer DJ (2005). Weight loss during pegylated interferon and ribavirin treatment of chronic hepatitis $C^{*}$. J Viral Hepat 12: 531-535.

Shuto H, Kataoka Y, Horikawa T, Fujihara N, Oishi R (1997). Repeated interferon-alpha administration inhibits dopaminergic neural activity in the mouse brain. Brain Res 747: 348-351.

Su KP, Huang SY, Peng CY, Lai HC, Huang CL, Chen YC et al (2010). Phospholipase A2 and cyclooxygenase 2 genes influence the risk of interferon-alpha-induced depression by regulating polyunsaturated fatty acids levels. Biol Psychiatry 67: 550-557.

Sunami M, Nishikawa T, Yorogi A, Shimoda M (2000). Intravenous administration of levodopa ameliorated a refractory akathisia case induced by interferon-alpha. Clin Neuropharmacol 23: 59-61.

Talpaz M, Kantarjian H, Kurzrock R, Trujillo JM, Gutterman JU (1991). Interferon-alpha produces sustained cytogenetic responses in chronic myelogenous leukemia. Philadelphia chromosome-positive patients. Ann Intern Med 114: 532-538.

Teva Pharmaceuticals USA Inc. (2011). Paroxetine. http:// www.drugs.com/pro/paroxetine.html.

Valentine AD, Meyers CA, Kling MA, Richelson E, Hauser P (1998). Mood and cognitive side effects of interferon-alpha therapy. Semin Oncol 25(Suppl 1): 39-47.

Vargas HE, Laskus T, Radkowski M, Wilkinson J, Balan V, Douglas $\mathrm{DD}$ et al (2002). Detection of hepatitis $\mathrm{C}$ virus sequences in brain tissue obtained in recurrent hepatitis $\mathrm{C}$ after liver transplantation. Liver Transpl 8: 1014-1019.

Vecsei L, Beal MF (1990). Influence of kynurenine treatment on open-field activity, elevated plus-maze, avoidance behaviors and seizures in rats. Pharmacol Biochem Behav 37: 71-76.

Walsh D, Donnelly S, Rybicki L (2000). The symptoms of advanced cancer: relationship to age, gender, and performance status in 1000 patients. Support Care Cancer 8: 175-179.

Walsh D, Rybicki L (2006). Symptom clustering in advanced cancer. Support Care Cancer 14: 831-836.

Wang XS, Fairclough DL, Liao Z, Komaki R, Chang JY, Mobley GM et al (2006). Longitudinal study of the relationship between chemoradiation therapy for non-small-cell lung cancer and patient symptoms. J Clin Oncol 24: 4485-4491.

Weissenborn K, Ennen JC, Bokemeyer M, Ahl B, Wurster U, Tillmann $\mathrm{H}$ et al (2006). Monoaminergic neurotransmission is altered in hepatitis $\mathrm{C}$ virus infected patients with chronic fatigue and cognitive impairment. Gut 55: 1624-1630.

Wheatley K, Ives N, Hancock B, Gore M, Eggermont A, Suciu S (2003). Does adjuvant interferon-alpha for high-risk melanoma provide a worthwhile benefit? A meta-analysis of the randomised trials. Cancer Treat Rev 29: 241-252.

Wichers MC, Koek GH, Robaeys G, Praamstra AJ, Maes M (2005). Early increase in vegetative symptoms predicts IFN-alpha-induced cognitive-depressive changes. Psychol Med 35: 433-441.

Wilkie MJ, Smith G, Day RK, Matthews K, Smith D, Blackwood D et al (2009). Polymorphisms in the SLC6A4 and HTR2A genes influence treatment outcome following antidepressant therapy. Pharmacogenomics J 9: 61-70.

Williams GW, Barton GM, White AA, Won H (1976). Cluster analysis applied to symptom ratings of psychiatric patients: an evaluation of its predictive ability. Br J Psychiatry 129: 178-185.

Yates WR, Gleason O (1998). Hepatitis C and depression. Depress Anxiety 7: 188-193. 
IFN- $\alpha$ and hepatitis-C: symptom dimensions and paroxetine

MD McNutt et al

Yonkers KA, Samson J (2000). Mood disorders measures. In: Rush AJ, Pincus HA, First MB, et al (eds) Handbook of Psychiatric Measures. American Psychiatric Association: Washington, DC. pp 515-549.

Yoon JC, Crane PK, Ciechanowski PS, Harrington RD, Kitahata MM, Crane HM (2011). Somatic symptoms and the association between hepatitis $\mathrm{C}$ infection and depression in HIV-infected patients. AIDS Care 23: 1208-1218.
Yoshida K, Alagbe O, Wang X, Woolwine B, Thornbury M, Raison CL et al (2005). Promoter polymorphisms of the interferonalpha receptor gene and development of interferon-induced depressive symptoms in patients with chronic hepatitis C: preliminary findings. Neuropsychobiology 52: 55-61.

Zdilar D, Franco-Bronson K, Buchler N, Locala JA, Younossi ZM (2000). Hepatitis C, interferon alfa, and depression. Hepatology 31: 1207-1211. 